\title{
Erratum to: Multiparametric magnetic resonance imaging for transition zone prostate cancer: essential findings, limitations, and future directions
}

Sara Lewis $\odot,{ }^{1,2}$ Cecilia Besa, ${ }^{2}$ Ally Rosen, ${ }^{1}$ Ardeshir R. Rastinehad, ${ }^{3}$ Sahar Semaan,,${ }^{1,2}$ Stefanie Hectors, ${ }^{2}$ Bachir Taouli ${ }^{1,2}$

${ }^{1}$ Department of Radiology, Icahn School of Medicine at Mount Sinai, 1 Gustave L. Levy Place, New York, NY 10029, USA

${ }^{2}$ Translational and Molecular Imaging Institute (TMII), Icahn School of Medicine at Mount Sinai, New York, NY, USA

${ }^{3}$ Department of Urology, Icahn School of Medicine at Mount Sinai, New York, NY, USA

Erratum to: Abdom Radiol (2017)

DOI 10.1007/s00261-017-1184-6

The original verison of this article unfortunately contains mistakes in the co-author names "Stephanie Hectors" and "Sahar Semann". The names should read as "Stefanie Hectors" and "Sahar Semaan". This has been corrected now with this erratum.

The original article was corrected.

The online version of the original article can be found under doi: 10.1007/s00261-017-1184-6. 